\title{
ELECTRON AND LIGHT MICROSCOPICAL STUDIES ON SPERMATELIOSIS IN A BOAR WITH ACROSOME ABNORMALITIES
}

\author{
ALLAN BANE AND LENNART NICANDER \\ Departments of Obstetrics and Gynaecology and of Anatomy and Histology, \\ Royal Veterinary College, Stockholm 50, Sweden
}

(Rereived 17th Fune 1965)

\begin{abstract}
Summary. The development of the acrosome was studied in three normal boars and in one sterile boar with acrosome abnormalities. These abnormalities appeared mainly during three stages of spermiogenesis: (1) in spherical spermatids during the late cap phase, as an invagination of the interior membrane of the acrosomic cap with concomitant sinking of the acrosomic granule into the depression thus formed; (2) in elongated spermatids during the late acrosome phase, as an asymmetrical, extensive, curved process into the Sertoli cell cytoplasm; and (3) during the maturation phase by persistence of a tongue-like protrusion of the acrosome normally present only during the late acrosome phase. It is suggested that the common feature of the different types is an abnormal growth tendency in the acrosomic system.
\end{abstract}

\section{INTRODUCTION}

Morphological abnormalities in the acrosome and nucleus of epididymal and ejaculated spermatozoa from a sterile boar of the Yorkshire breed have been described by Bane (1961). Since then three more boars with acrosomal abnormalities have been found, two of the Yorkshire breed and one of the Swedish Landrace breed. Moreover, while searching the sperm smears stored in the semen laboratory of the Department of Obstetrics and Gynaecology, Royal Veterinary College, Stockholm, the authors observed similar acrosome aberrations in three more boars of the Swedish Landrace breed, examined for sterility in 1949, 1951 and 1956. Obviously, acrosome abnormalities have occurred in Swedish boars for many years, though apparently at a low frequency.

Very few reports of acrosome abnormalities in boars have been found in the literature. Aberrations have been reported from Germany (Liess \& Krause, 1958; Wohlfart, 1961) and have also been observed in Great Britain (Madden, 1962, personal communication, Hancock, 1962, personal communication). On the other hand, many cases of acrosome abnormalities ('knobbed spermatozoa') have been reported for bulls, generally of the Friesian breed (Teunissen, 1946; 
Hancock, 1949; Rollinson \& Makinson, 1949; Schulte \& Ehrlich, 1954; Bonadonna, 1955; Jaskowski \& Romaniuk, 1959). Only isolated cases have been reported for other breeds (Blom, 1948; Aamdahl, 1951). In the case of Friesian bulls, the hereditary character of the aberration has been proved by Donald \& Hancock (1953). Rajasekarasetty (1954) and Hollander, Bryan \& Gowen, (1960) have described abnormalities in the acrosome and the nucleus in mice with hereditary sterility.

It is characteristic of the cases reported that the abnormality occurred in a variable, but generally very high, proportion of the spermatozoa and, as a rule, was associated with total sterility. On the other hand, a low frequency ( 1 to $2 \%$ ) of abnormal acrosome development can be found in seminiferous tubules and even in ejaculates from some animals which show apparently normal fertility. The present authors have seen such cases in stallions, rams, dogs, cats, rats, mice and, very often, in rabbits.

Since the abnormalities occur in several mammals and are related to sterility, the mode of their formation is of considerable interest for comparative pathology. Hancock \& Trevan (1957) made a thorough study of normal and abnormal development of the acrosome in bulls. They considered the abnormality to be the result of an incomplete spreading over the anterior pole of the nucleus of one of the two acrosome components, the 'bead'. In the abnormal spermatids this 'bead' persisted during the later stages of spermateliosis as the 'knob', a region in the most anterior part of the sperm head which had an irregular shape and was strongly stained by the periodic acidSchiff reagent. From histological investigations of the testes of one bull, Tiba (1964) related the defect to a strong bending of the acrosome along the side of the sperm head occurring during the maturation phase. No electron microscopical studies on the development of acrosome aberrations could be found in the literature.

The present paper gives an account of light and electron microscopical studies of the development of the acrosome in a boar with different types of acrosome abnormalities. Normal material from healthy, fertile boars was also studied for comparison.

\section{MATERIALS AND METHODS}

Material was collected from three normal boars and the boar with acrosome abnormalities already described by Bane (1961). Castration was performed under local anaesthesia, and small pieces of tissue were rapidly cut out from the testis and fixed for $1 \mathrm{hr}$ in a cold $2 \%$ solution of osmium tetroxide, buffered

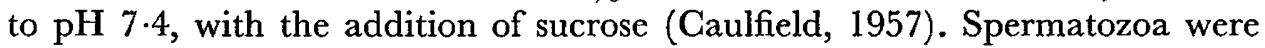
taken out with a pipette from small incisions in the epididymal tail and allowed to spread on small paper strips, which were then placed on the surface of the same fixation fluid, at room temperature. The material was embedded in Epon (Luft, 1961) or in a mixture of methyl and ethyl methacrylate, 1:4. Sections were cut with glass knives on an LKB Ultrotome. For surveying, sections were cut at about $1 \mu$, stained with toluidine blue and studied in the light microscope. Thinner (golden) and smaller sections for electron microscopy were cut from 
selected areas. Those embedded in Epon were picked up on naked copper grids and 'stained' with uranyl acetate. Methacrylate sections were placed on formvar coated grids and studied without further treatment. A Siemens Elmiskop I was used, at 60 or $80 \mathrm{kV}$. The original magnification varied from 2000 to 12,500 diameters.

Material for conventional light microscopy was taken from the testis and the head and tail of the epididymis, fixed in Bouin's or Helly's fluids and embedded in paraffin. Sections $5 \mu$ in thickness were stained with haemalum and eosin or with the periodic acid-Schiff reagent.

\section{OBSERVATIONS}

The developing acrosome of the spermatid can be described as consisting of two parts: the acrosomic granule and the acrosomic vacuole or cap. These terms correspond approximately to the inner and the outer zone of the proacrosome as described by Bishop \& Walton (1960). The electron microscope shows that the acrosomic granule is contained within the vacuole. The nomenclature of Clermont \& Leblond (1955) is used for the stages of the cycle of the seminiferous epithelium.

\section{Survey of the development of the normal acrosome}

The Golgi apparatus of very young spermatids contains some small, electron dense granules, each one within a vacuole. By confluence of these smaller units, one large vacuole containing a large granule is formed. It moves to the nucleus and the granule, still within its vacuole, makes contact with and causes a shallow depression in the periphery of the nucleus. Then the vacuole slowly flattens and spreads until it covers about half the nuclear surface, while its contents become more opaque (Pl. 1, Fig. 1). This development takes place in the still spherical spermatids and is completed at the end of a cycle of the seminiferous epithelium.

The next cycle starts with a rotation of all the spermatid nuclei, causing the acrosomic granule to point towards the nucleus of the Sertoli cell. The following stage shows an elongated, columnar nucleus, and the acrosomic granule, still surrounded by a rim of opaque vacuolar contents, enlarges and forms the core of a blunt projection. The posterior border of the acrosomic cap spreads further backwards until it covers about two-thirds of the nuclear surface.

The nucleus undergoes a progressive flattening and a slow condensation of its chromatin, while the acrosomic projection broadens and expands along the anterior edge of the nucleus until it forms a tongue-like protrusion, slightly oval in profile view (Pl. 1, Fig. 3). This protrusion then becomes more elongated and flattened and appears asymmetrical and finger-like in profile view (Pl. 1, Fig. 5). The thin protrusion then retracts and only a slightly asymmetrical acrosomal thickening along the anterior edge of the nucleus persists, mainly on the convex side of the slightly bent tip of the nucleus (Pl. 2, Fig. 6).

The equatorial segment is formed by a sudden decrease in thickness of the posterior part of the acrosomic cap. 
Development of abnormal acrosomes

The abnormalities observed can be subdivided into three main types.

The first type, which is by far the most frequent, is characterized by a persistence of the normally transitory tongue-like acrosomal projection throughout the remaining stages of spermateliosis (Pl. 2, Figs. 7 and 9a), apparently without modification of the nuclear structure. Thus spermatozoa just before shedding show in surface view a weakly stainable 'tongue' protruding from the anterior margin of the nucleus. In profile view this 'tongue' appears as a fingerlike projection, sometimes very long (Pl. 2, Fig. 9a). Moreover, no equatorial segment is formed, but the posterior part of the acrosome appears thickened (Pl. 2, Fig. 7).

The second type first appeared in spherical spermatids, generally in all cells within a tubular area. The shallow depression in the nucleus caused by the acrosomic granule within its vacuole is not reduced as in normal development. Instead, a deeper invagination is formed until the whole of the acrosomic granule is contained inside the periphery of the nucleus (Pl. 1, Fig. 2). The granule remains in this position throughout spermateliosis, obviously preventing the normal flattening of the anterior part of the sperm head (Pl. 2, Fig. 9b; Pl. 3, Figs. 10 and 12).

The third type is less regular. Most often, it seemed to start as an overgrowth and lateral displacement of the acrosomic projection during the late acrosome phase (Pl. 2, Fig. 8). Later on, this enlarged projection becomes curved or curled, sometimes even pinching off parts of the Sertoli cell cytoplasm which are transported with the spermatozoa into the epididymis (Pl. 3, Fig. 12). Spermatozoa with this type of aberrant acrosome also show an abnormal nuclear shape. Sometimes abnormalities of a similar type were formed before the stage of the projection was reached (Pl. 1, Figs. 4a, 4b and 5). Finally, spermatozoa with a combination of two types of abnormalities were sometimes observed (Pl. 1, Fig. 4b; Pl. 2, Fig. 9b; Pl. 3, Fig. 12).

\section{Structure of abnormal epididymal spermatozoa.}

The only other acrosomal aberration which was observed within the epididymis, consisted of a backward folding of the persisting acrosomal protrusion along the convex flattened surface of the sperm head (Pl. 3, Figs. 11 and 13). The observations made on epididymal spermatozoa did not add any important information to that already given by Bane (1961).

\section{DISCUSSION}

The light microscopical observations made in this study on the development of the acrosome of normal boar spermatozoa are in good agreement with the reports by Hancock (1957) and Lovell \& Getty (1960) and show that the process is similar to that in rams as described by Clermont \& Leblond (1955). However, the thin, transitory acrosomal projection has apparently only been reported by Hancock \& Trevan (1957) in bulls and by Hancock (1957) in boars. These authors described the projection as occurring in late spermatids while we observed it in an intermediate stage of spermateliosis. Recent electron micro- 


\section{EXPLANATION OF PLATES}

Main symbols used: $\mathrm{A}=$ acrosome, $\mathrm{Ag}=$ acrosomic granule, $\mathrm{Av}=$ acrosomic vacuole, $c=$ cell membrane, $\mathrm{g}=$ Golgi apparatus, $\mathrm{N}=$ nucleus, $\mathrm{P}=$ protrusion of the acrosome, $\mathrm{S}=$ Sertoli cell cytoplasm, $\mathrm{T}=$ proximal part of the sperm tail.

\section{PLATE 1}

Fig. 1. Nucleus and acrosomic system of a normal spermatid in late cap phase. Epon. $\times 11,000$.

Fig. 2. Abnormal spermatid at the same stage as that in Fig. 1, with sunken acrosomic granule. Methacrylate. $\times 12,000$.

FIG. 3. Normal acrosomal region in early acrosome phase. Methacrylate. $\times 14,000$.

Fig. 4a. Abnormal spermatid in early acrosome phase. The acrosome appears to be shortened, and its apical part contains invaginated Sertoli cell cytoplasm (Si). Methacrylate. $\times 14,000$.

FIG. 4b. Abnormal spermatid in early acrosome phase with a vacuole (v), probably containing some Sertoli cell cytoplasm, in the acrosome, and an intranuclear acrosomic granule. Methacrylate. $\times 15,000$.

FIG. 5. Parts of two normal, immature sperm heads in late acrosome phase. The nuclear ring (NR) is still present and an apical acrosomal protrusion has formed. Epon. $\times 16,000$.

\section{PLATE 2}

Figs. 6-8. Electron micrographs of spermatid nuclei at the same stage of spermateliosis (early maturation phase) as 4 b. Epon. $\times 15,000$.

FIG. 6. Normal spermatid. The acrosome protrusion and the nuclear ring have disappeared.

Fig. 7. Abnormal acrosome system with a persisting apical protrusion and a thickening of the posterior region of the acrosome cap.

Fig. 8. Abnormal nucleus (oblique section) with a large, folded acrosomal process (AF). A cross-section of the apical acrosome region of another spermatid is also seen (bottom left). It contains invaginated Sertoli cell cytoplasm.

Figs. 9a and 9b. Photomicrographs of sections of the testis from a boar with acrosomal abnormalities. Helly. Haematoxylin and eosin. $\times 1200$.

Fic. 9a. Abnormal spermatid with a long acrosomal protrusion (arrow).

Fig. 9b. Abnormal spermatids with nuclear aberrations invaded by acrosomic granule. One spermatid with a membrane-like acrosomal protrusion from the apex to the base (arrow).

\section{PLATE 3}

FIGs. 10-12. Electron micrographs of abnormal cells. Epon.

Fic. 10. Parts of two adjacent immature sperm heads in maturation phase. The one on the left shows an invaginated acrosomic granule and an abnormal nuclear shape. That on the right has a persisting acrosomic protrusion. $\times 15,000$.

Frg. 11. Head of epididymal spermatozoa, with a folded acrosomic protrusion and a thickening of the posterior acrosomic cap region (arrow) instead of an equatorial segment. $\times 15,000$.

Fig. 12. Highly distorted head of an epididymal spermatozoon. The acrosomic granule is invaginated, but connected with the acrosomic cap (arrow). An apical double fold of the acrosomic cap forms a vesicle, probably containing Sertoli cell cytoplasm. $\times 30,000$. Fic. 13. Photomicrograph of epididymal spermatozoa with different types of acrosomal abnormalities. Phase-contrast. $\times 1200$.

(Facing p. 136) 
PLATE 1

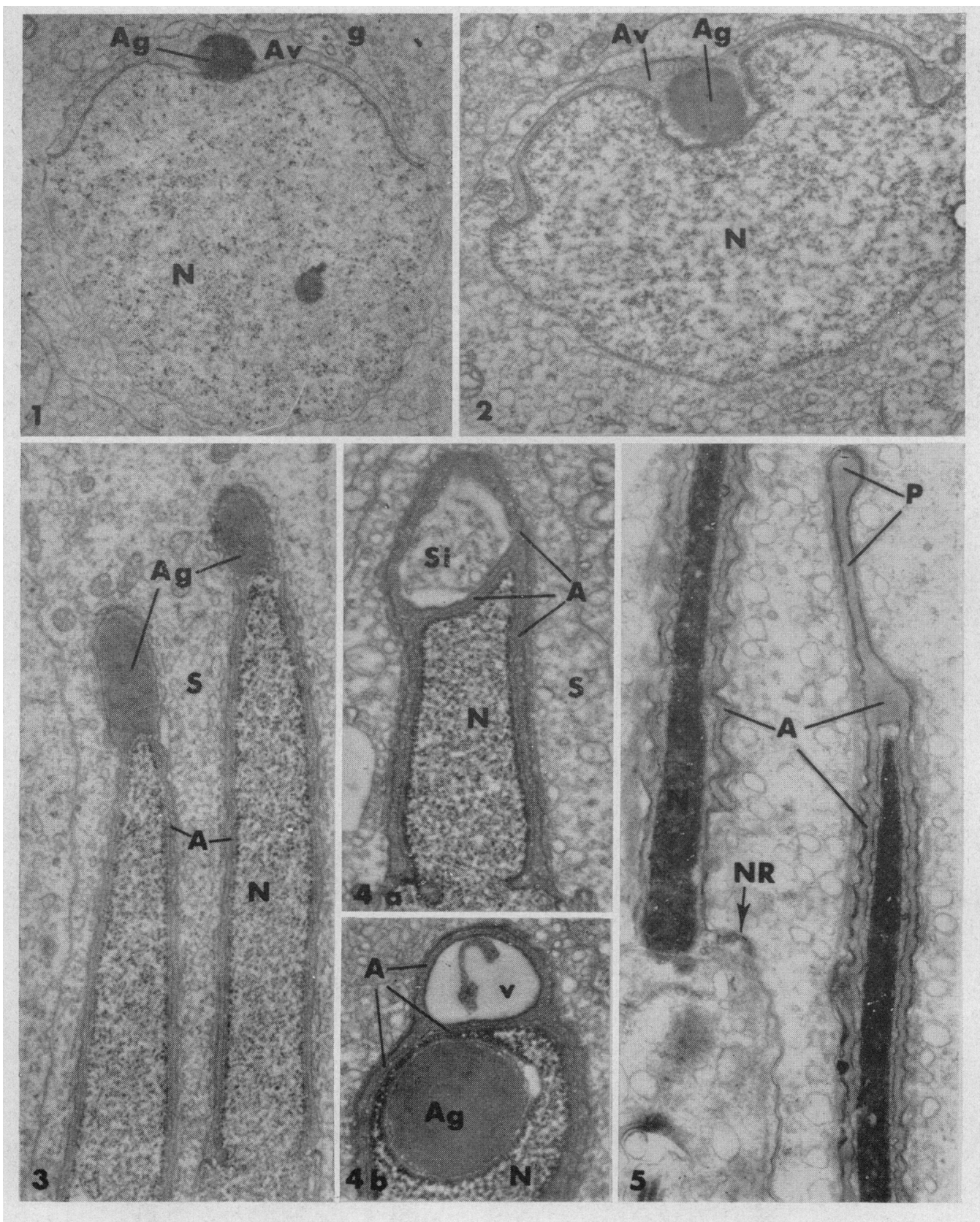


PLATE 2

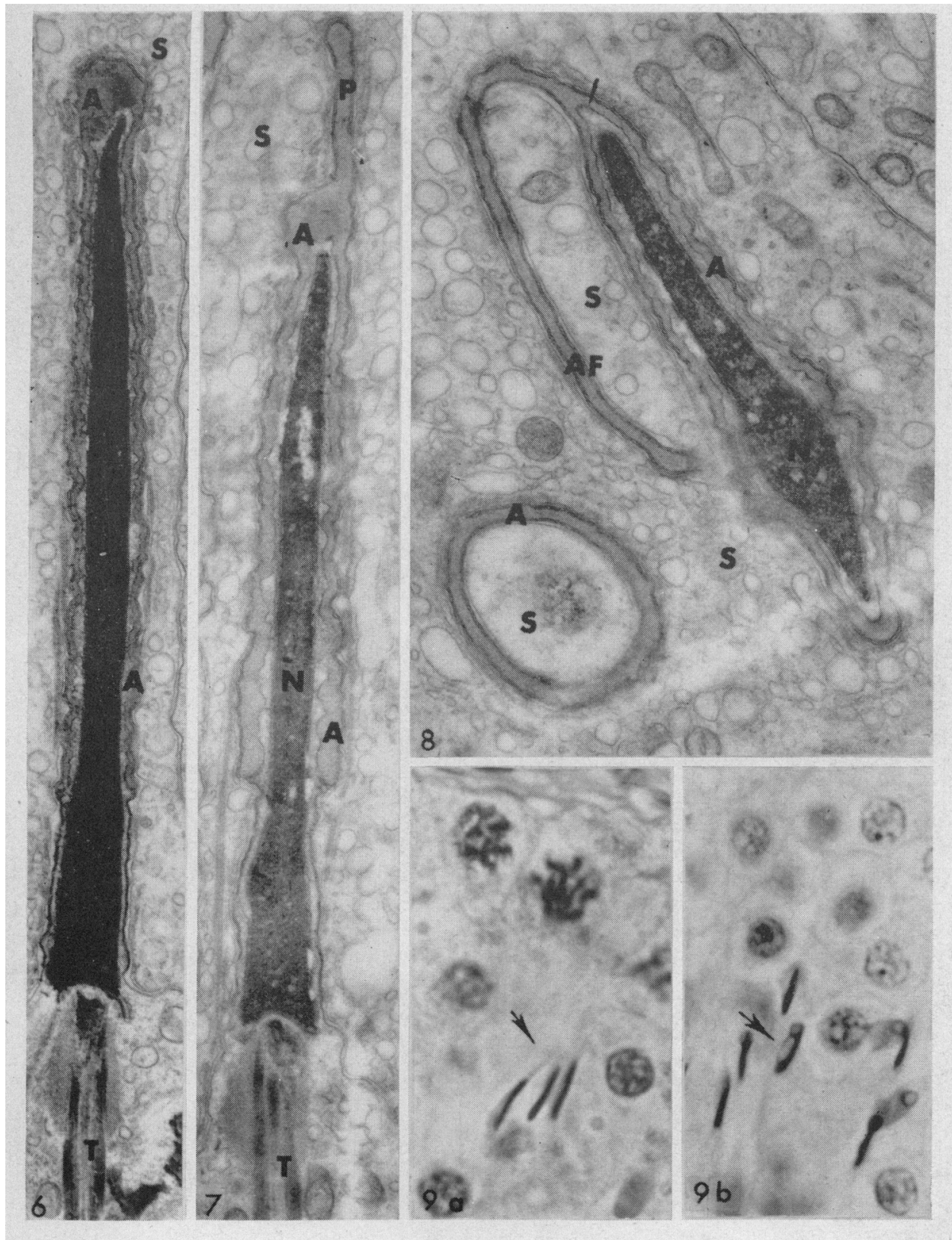


PLATE 3

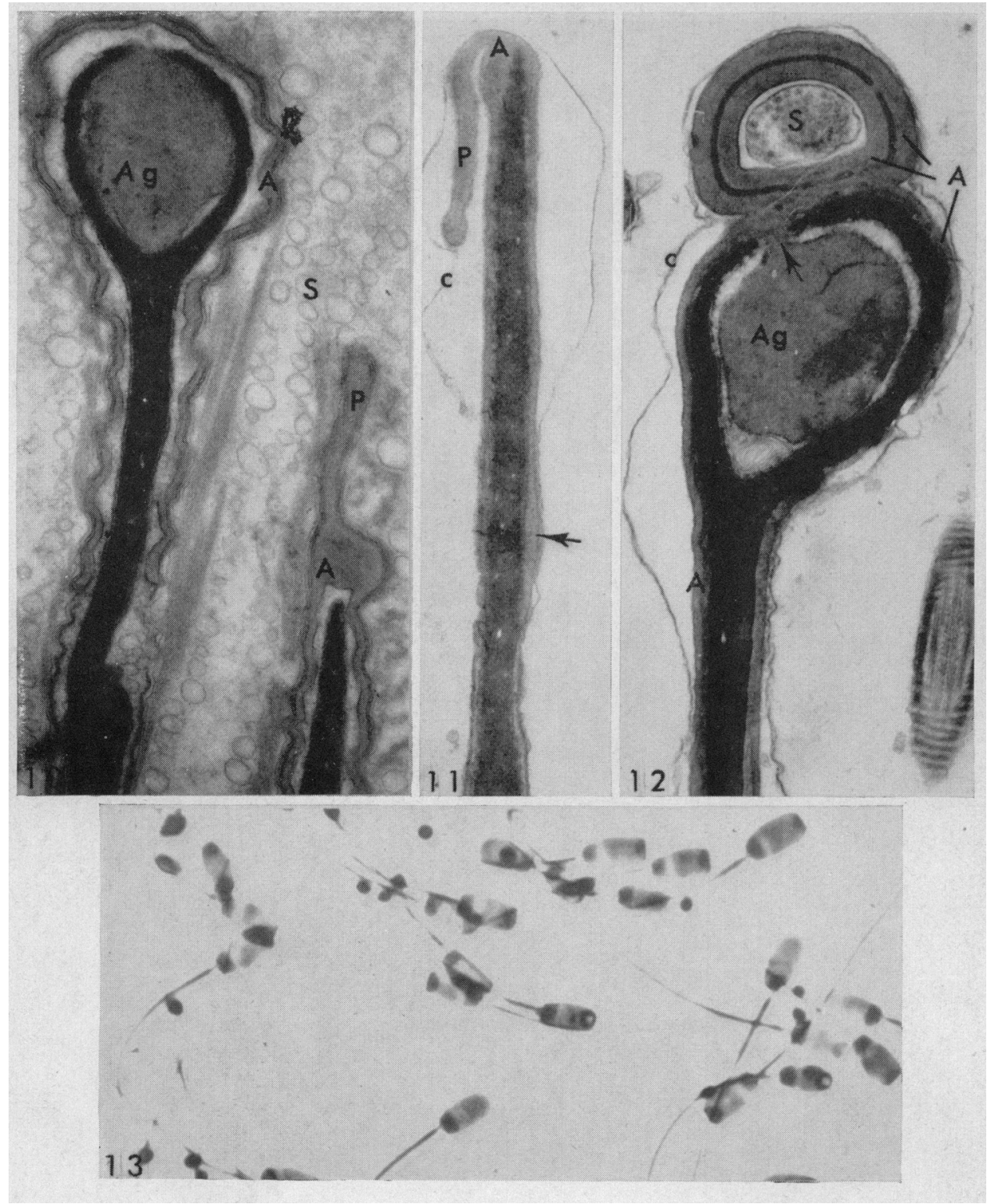


scopical studies on spermateliosis have shown a similar structure in rams, dogs and rabbits (Nicander, unpublished observations). In addition to this new feature, the present short survey of normal acrosome development, as seen with the electron microscope, also differs from those given by Burgos \& Fawcett (1955) for cat and by Horstmann (1961) for human spermatids regarding the latest stages of spermateliosis. An equatorial segment was not observed in these species, the ultimate fate of the acrosomic granule was not described in cats, and in human spermatozoa this granule finally coalesced with the cap. The present results are in agreement with those of Hancock (1957) regarding the late appearance of the equatorial segment, but Hancock's interpretation of the segment as an area only covered by one of two acrosomal components could not be verified. The electron micrographs clearly demonstrate that the acrosome is a single, membrane-bounded unit and the nature of the equatorial segment in nearly mature spermatozoa was found to be the same as in epididymal spermatozoa (Nicander \& Bane, 1962).

The three main types of acrosome abnormalities observed during spermiogenesis may all be caused by one common factor: a tendency towards uncontrolled growth in the acrosomal system. If this tendency is already manifest in spherical spermatids, the nuclear envelope is invaginated by the inner membrane of the acrosomic cap and the acrosomic granule sinks into the invagination. In elongated spermatids the condensed nucleus is more solid and resistant and the abnormal growth takes place into the surrounding cell cytoplasm as an irregular protrusion. Finally, in advanced stages of spermateliosis the whole acrosome appears to be more solid and the abnormal tendency only prevents the completion of normal development, so that the mature sperm nucleus has an immature acrosome. The young, elongated spermatids with abnormal acrosomes apparently invaded by Sertoli cell cytoplasm, without the formation of protrusions (Pl. 1, Fig. 4), do not belong to any of the types described, and it seems difficult to fit this aberration into the theory just advanced. However, during this phase of spermiogenesis, the Sertoli cell cytoplasm normally sends long processes into the cytoplasm of the elongated spermatids. The aberration may be formed by such a process invading an acrosomic vacuole with less than normal stability. This type of acrosomal abnormality has been observed much more frequently in another sterile boar and will be described in more detail elsewhere.

The development of acrosome abnormalities ('knobbed' spermatozoa) in bulls was studied by Hancock \& Trevan (1957), who found that the aberration appeared late in spermateliosis as the 'bead' did not spread over the anterior pole of the nucleus. This description may indicate a similarity between the abnormality seen in bulls and the persistent protrusion type of aberration (type one) observed in the boar.

The bending of the persistent protrusion which obviously takes place in the epididymis seems less surprising in the light of some recent studies on acrosome morphology in epididymal spermatozoa. Fawcett \& Hollenberg (1963) observed distinct changes in the ultrastructure of the acrosome of guinea-pig spermatozoa during their passage through the epididymis and Bedford $(1963,1964)$ observed still more striking modifications in the size and shape of the acrosome in epididymal spermatozoa of rabbits. 


\section{REFERENCES}

AAMDAHL, J. (1951) Forandring i spermienes kromatinsubstans og i galea capitis som ársak til sterilitet hos okse. Nord. Vet. Med. 3, 102.

BAne, A. (1961) Acrosomal abnormality associated with sterility in boar. Proc. IVth int. Congr. Anim. Reprod., The Hague, Vol. IV, p. 810.

BEDFORD, J. M. (1963) Morphological changes in rabbit spermatozoa during passage through the epididymis. 7. Reprod. Fert. 5, 169.

BEDFORD, J. M. (1964) Changes in fine structure of the rabbit sperm head during passage through the epididymis. Proc. 5th int. Congr. Anim. Reprod., Trento, Vol. III, p. 397.

Bishop, M. W. H. \& Walton, A. (1960) Spermatogenesis and the structure of mammalian spermatozoa. Marshall's Physiology of Reproduction, vol. 1, part 2, p. 1. Ed. A. S. Parkes. Longmans Green, London.

Bцом, E. (1948) Om spermaundersøgelsemetoder hos Tyren. Medlemsbl. danske Dyrlaegeforen. 31, 446.

Bonadonna, T. (1955) Di una particolare Formazione alla Testa dei Nemaspermi Bovini (Knobbed) Messa in Evidenza al Microscopia Elettronico. Riv. Biol. 47, 297.

Burgos, M. H. \& FawcetT, D. W. (1955) Studies on the fine structure of the mammalian testis. 7. biophys. biochem. Cytol. 1, 287.

Caulfield, J. B. (1957) Effects of varying the vehicle for $\mathrm{OsO}_{4}$ in tissue fixation. 7. biophys. biochem. Cytol. 3, 827.

Clermont, Y. \& Leblond, C. P. (1955) Spermiogenesis of man, monkey, ram and other mammals as shown by the 'Periodic acid-Schiff' technique. Am. F. Anat. 96, 229.

Donald, H. P. \& Hancock, J. L. (1953) Evidence of a gene-controlled sterility in bulls. F. agric. Sci. Camb. 43, 178.

Fawcett, D. W. \& Hollenberg, R. D. (1963) Changes in the acrosome of guinea pig spermatozoa during passage through the epididymis. Z. Zellforsch. mikrosk. Anat. 60, 276.

HANCOCK, J. L. (1949) Evidence of an inherited seminal character associated with infertility of Friesian bulls. Vet. Rec. $61,308$.

HANCOCK, J. L. (1957) The morphology of boar spermatozoa. fl R. microsc. Soc. 76, 84.

Hancock, J. L. \& Trevan, D. J. (1957) The acrosome and post-nuclear cap of bull spermatozoa. Jl R. microsc. Soc. 76, 77.

Hollander, W. F., Bryan, J. H. D. \& Gowen, J. W. (1960) A male sterile pink-eyed mutant type in the mouse. Fert. Steril. 11, 316.

Horstmann, E. (1961) Elektronenmikroskopische Untersuchungen zur Spermiohistogenese beim Menschen. Z. Zellforsch. mikrosk. Anat. 54, 68.

JAskowski, L. \& Romaniuk, J. (1959) A rare sperm-anomaly associated with complete sterility in a bull. Med. vet. 15, 760 .

Liess, J. \& Krause, D. (1958). Zum Vorkommen des sogenannten 'Akrosom-Defektes' im Ebersperma. Dt. tierärztl. Wschrft. 65, 677.

Lovelt, J. E. \& GeTTY, R. (1960) Cytochemical reactions of porcine spermatids and spermatozoa. Am. 7. vet. Res. 21, 597.

LuFT, J. H. (1961) Improvements in epoxy resin embedding methods. F. biophys. biochem. Cytol. 9, 409.

NicANDER, L. \& BANE, A. (1962) Fine structure of boar spermatozoa. Z. Zellforsch. mikrosk. Anat. 57, 390.

RAJASEKARASETTY, M. R. (1954) Studies on a new type of genetically determined quasi-sterility in the house mouse. Fert. Steril. 5, 68.

Rollinson, D. H. L. \& Makinson, J. B. (1949) Evidence of an inherited seminal character associated with infertility of Friesian bulls. Vet. Rec. 61, 373.

Schulte, F. \& EHrLich, J. (1954) Impotentia generandi eines Jiungbullen infolge Akrosom-Defekts der Samenzellen. Dt. tierärztl. Wschr. Beilage Fortpfl. Zuchthyg. Haustierbesamung, 4, 90.

Teunissen, G. H. P. (1946) Een afwijkning van het acrosom (kopkap) bij de spermatozoiden van een stier. Tijdschr. Diergeneesk. 71, 292.

TiBA, T. (1964) Histologische Beobachtungen der Spermiogenese beim sogenanten 'Akrosom-Defekt' des Bullenspermiums. Fap. F. vet. Res. 12, 25.

Wohlfart, E. (1961) Beitrag zum Akrosom-Defekt im Ebersperma. Zucht-hyg. Fortpfl. Stör. Besam. Haustiere, 5, 268. 